\begin{tabular}{ll} 
O P E R A T I O N S R E S E A R C H A N D D E C I S I O N S \\
\hline No. 2
\end{tabular}

DOI: $10.37190 /$ ord200202

\title{
PERSONALISATION OF PRODUCTION IN THE ERA OF INDUSTRY 4.0 AS A CHALLENGE FOR INVENTORY MANAGEMENT IN SMALL AND MEDIUM-SIZED PRODUCTION ENTERPRISES
}

\author{
SANDRA GRABOWSKA* \\ Silesian University of Technology, ul. Krasińskiego 8, 40-019 Katowice, Poland
}

\begin{abstract}
Industry 4.0 is the result of the development of cyber-physical generation systems as a part of the fourth industrial revolution. Industry 4.0 sets new areas for change in the sphere of production and management but also influences various aspects of society. Industry 4.0 is focused on continuous improvement of production processes. This is a turnaround in the production control methodology, as the growing expectations of customers in the modern market cause, along with the increase in production efficiency, customisation of the product. In this trend, the customer decides about the product, personalising it as much as possible and in the best possible way. These are new challenges in the field of inventory management. The article aims to present a method of calculating the optimal amount of the cost of a rotating stock in a production enterprise with an unevenly distributed demand, which is the case with personalised orders.
\end{abstract}

Keywords: inventory, personalisation, customisation, Industry 4.0, small and medium-sized enterprises (SMEs)

\section{Introduction}

The contemporary nature of production is shaped by changing the paradigm from mass production to production at the customer's request. The name Industry 4.0 has been used since 2000. Industry 4.0 marks the fourth industrial revolution in which it is assumed that it is a vision of intelligent factories built of intelligent cyber-physical systems. The implementation of this idea should enable the development of intelligent production systems which, in addition to the aforementioned autonomy, will have the features of self-configuration, self-control, and self-education $[2,3]$.

*Email address: sandra.grabowska@polsl.pl

Received 23 April 2019, accepted 3 July 2020 
Strong competition and growing customer expectations in the modern market mean that along with the increase in production efficiency, product customisation takes place, i.e., the production in which the customer decides about the product [1]. At the same time, the price of the product should be close to the price of products produced in mass production. This is exactly what the industry 4.0 concept provides, which assumes the creation of a fully integrated system of suppliers, producers and clients creating so-called cyberphysical (CPS) systems, which are open socio-technical systems, capable of implementing several functions and actions imposed by production, logistics or management. This situation brings new challenges in the area of inventory management [13]. As a result, production speed will increase by around $30 \%$ and productivity by at least $25 \%$. At the same time, complaints will be eliminated, and material saving will be noticeable [4]. A characteristic feature of Industry 4.0 will be fast and individual products for the customer's needs, not cheap and not massive [22].

Changes in production processes will only be possible if proper tools for a rapid redefinition of production are guaranteed, for which the company's logistics department must be prepared. Industry 4.0 is changing the way we work across the supply chain. Using AI, sensors and Internet of Things (IoT) technology, a smart and data-driven distribution centre can be developed by, for example, cross-referencing enterprise resource planning (ERP) systems with consumer trends data [17].

Stocks are one of the components of the analysis of management efficiency in the production process. One of the most important elements of logistic processes at every stage of the functioning of production enterprises, i.e., in procurement, production and distribution, are stocks. Thanks to them, materials flow efficiently and can also play an important role in situations of risk and uncertainty [10-12].

The primary goal of inventory management is the ability to react responsibly to the changes in demand, but, at the same time to lower the maintenance of inflated stocks. Concerning quality, a certain level of customer service, both internal and external, can be provided. Another important goal is to avoid excess and bottlenecks in the production process by tracking the current and future demand for all necessary goods [1].

The most important thing in stock management is the ability to make four important decisions. The first one is to indicate the materials in which stocks will be maintained. The next decisions are to determine the method of inventory control, the size of the batch of deliveries or production, as well as to assess how long the order will be processed. For such decisions, it is very important to distinguish the types of demand [4]. Industry 4.0, referred to as the upcoming future of production, raises the question of what changes companies and managers are waiting for. Adapting small and medium-sized enterprises to the conditions of Industry 4.0 raises many concerns, requires solving many problems and generates the need to build various tools, supporting, among others, warehouse management.

The article aims to present the method of calculating the optimal amount of the cost of a rotating stock in a production enterprise with an unevenly distributed demand, which is the case with personalised orders. 


\section{Review of the subject literature. Personalised production management in the era of Industry 4.0}

The Fourth Industrial Revolution, like the previous three revolutions, is a challenge for enterprises. Industry 4.0 results in a change in the production paradigm in favour of non-standard (personalised) production, tailored to the individual needs of customers. The ability to offer customers highly personalised products at low prices causes changes in the organisation of the entire production cycle, logistics, and management $[16,20]$.

Thanks to the development of ICT networks, it is possible to create a fully integrated system of suppliers, producers and customers, operating in open virtual networks. According to this concept, ICT-based solutions will be integrated with all subsystems, production and logistics processes, system resources and networks of suppliers and customers. Therefore, newly designed ICT systems will integrate entire supply chains, creating Cyber-Physical Systems (CPS), which are open social engineering systems [15]. CPS systems should ensure the collection of large amounts of data, their processing and impact on physical processes throughout the enterprise network employing an unlimited number of network connections at the same time [22]. One of the assumptions of the transformation within Industry 4.0 is the use of CPS mechatronic products (machines, devices, robots, means of transport, etc.) intensively employing them to create new personalised products, virtual documentation, models in 3D printing technology, product manufacturing in a virtual production environment, checking its correctness, transition from the virtual production environment to the real environment, with the active participation of the customer affecting the product design and production process. This means that it will be possible to meet the consumer's expectations thanks to the dynamic adaptation of the autonomous modules of the entire production preparation process, production, and delivery of the product to the consumer [21].

In the era of Industry 4.0, mass customisation of products and services is to become more beneficial than mass production. Changes introduced in the production processes are to enable the implementation of activities in the design and manufacture of the product initiated by the customer [23]. Personalisation of production can take different forms, depending on the degree of customer influence on the new product $[5,6,14]$. The highest degree of customer interference (the most expensive and the most difficult to organise) occurs in the case of pure customisation, in which the customer participates in the product design phase and has an impact on the product production process and distribution. An easier way to organise product customisation is tailored customisation, where the customer is involved in the product production phase and has an impact on the shape and dimensions of standard product components [19]. A more limited customer impact on the manufacturing process can be seen in the customised standardisation strategy, where the customer has an impact on assembly or distribution by selecting 


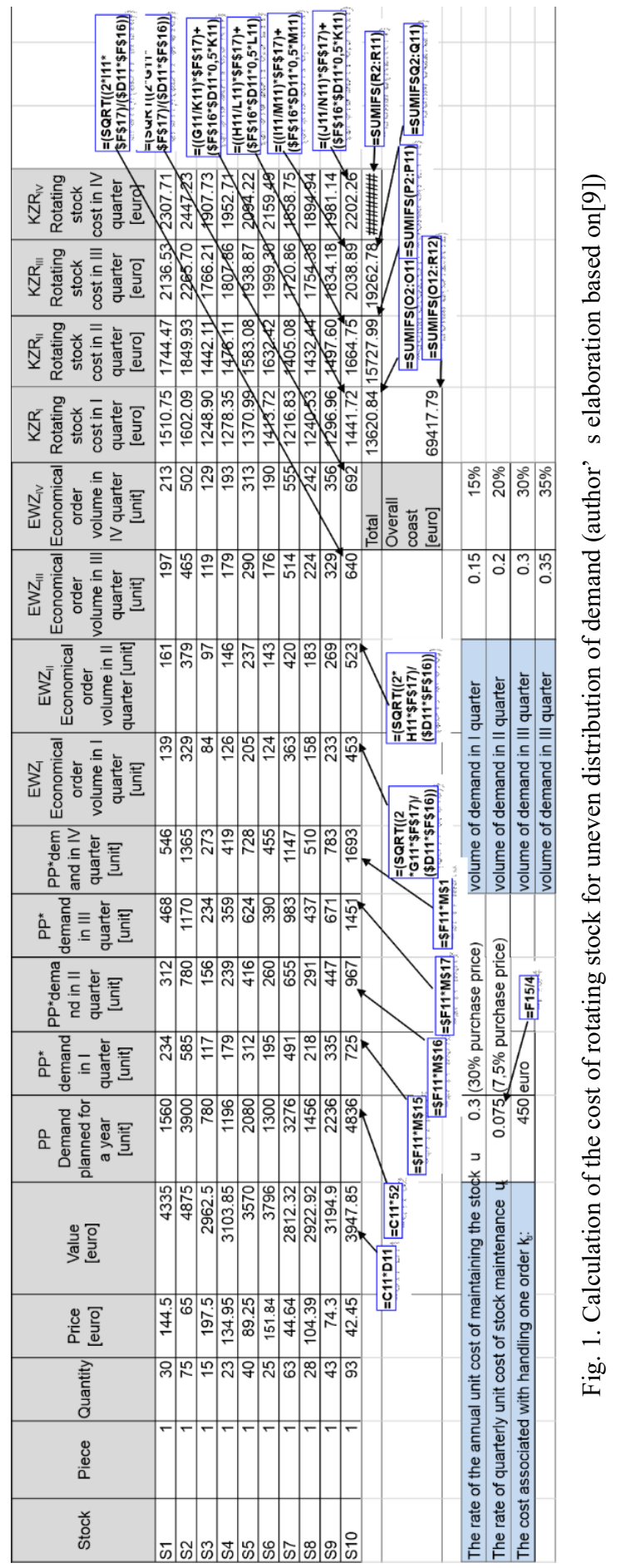




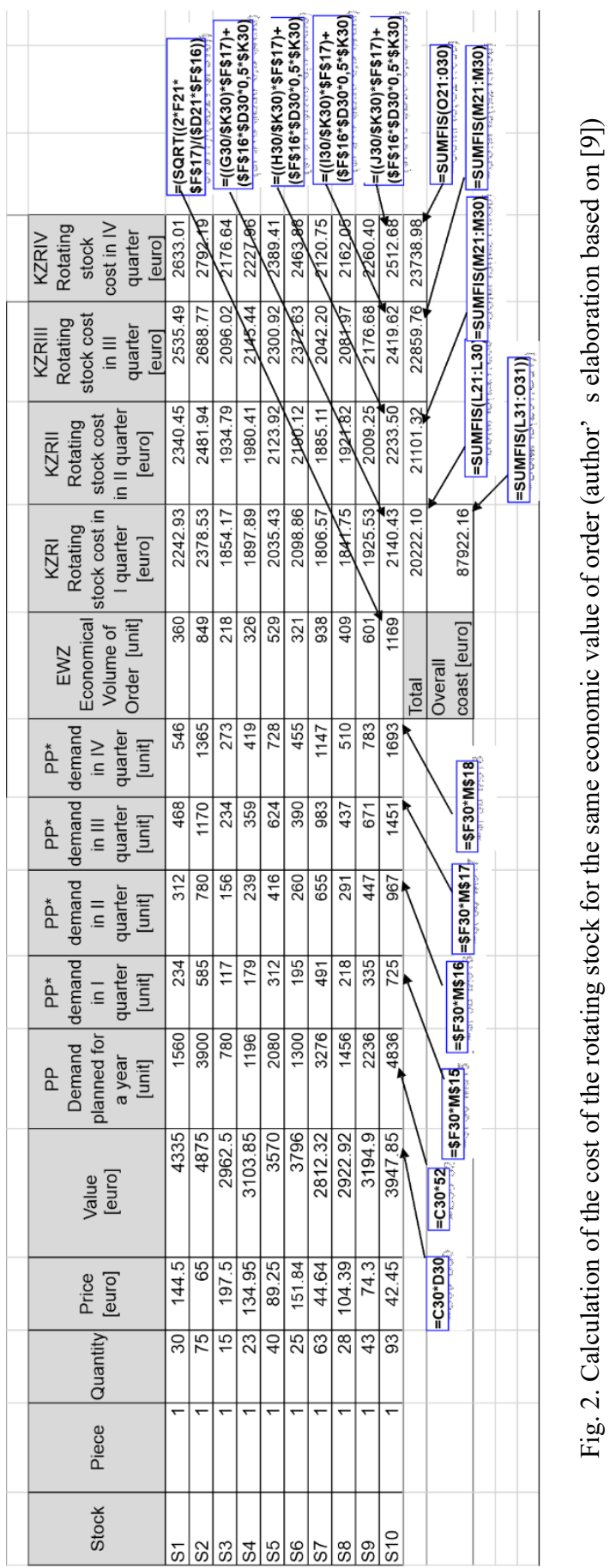


the available configuration options for the standard product. In both types of customization, the price of the product must be close to the price of the product offered in massproduction or mass Production [7]. This type of production is a big challenge for inventory management [18].

\section{Research method and result}

The rotary inventory is primarily associated with regular consumption as well as with the supplies that are intended to cover anticipated and current demand. It is renewed based on the information level and periodic review. Under the Industry 4.0 concept, enterprises will be forced to dynamically change the size and type of rotating stock [8].

The article uses data from a medium-sized production enterprise. Due to the limited possibility of publishing the data in the article, the details that identify the examined enterprise have been omitted. The study shows how the cost of the rotating stock will look like when demand is unevenly distributed, which happens in the case of customising the product. The adopted period will be three months because the planned demand is unevenly distributed (every quarter) during the year. Table 1 shows the demand in each quarter. Wilson's formula for the economic size of the order was also used in the calculation, but taking into account that the adopted period is not a year, but quarters.

Table 1. Demand distribution throughout the year

\begin{tabular}{|l|c|c|}
\hline Volume of demand: quarter I & 0.15 & $15 \%$ \\
\hline Volume of demand: quarter II & 0.2 & $20 \%$ \\
\hline Volume of demand: quarter III & 0.3 & $30 \%$ \\
\hline Volume of demand: quarter IV & 0.35 & $35 \%$ \\
\hline
\end{tabular}

The following relationships were used [8]:

- Economical volume of the order $(E W Z)$

$$
E W Z=\sqrt{\frac{2 P P_{o} k_{u}}{C u_{o}}}
$$

- The cost of a rotating inventory in a given quarter $(K Z R)$

$$
K Z R=\frac{P P_{o} k_{u}}{E W Z}+0.5 u_{o} C E W Z
$$

where $P P_{o}$ - planned demand, $k_{u}-$ cost per delivery, $C$ - purchase price, $u_{o}$ - periodic stock-holding ratio, 
- Total cost

$$
\begin{gathered}
K Z R^{\prime}=\sum K Z R^{\prime} \mathrm{I}+\sum K Z R^{\prime} \mathrm{II}+\sum K Z R^{\prime} \mathrm{III}+\sum K Z R^{\prime} \mathrm{IV} \\
K Z R^{\prime}=87922.16 \\
K Z R=\sum K Z R \mathrm{I}+\sum K Z R \mathrm{II}+\sum K Z R \mathrm{III}+\sum K Z R \mathrm{IV} \\
K Z R^{\prime}-K Z R=18504.36
\end{gathered}
$$

When comparing total costs in both cases, it can be noticed that the costs in the second situation increased by approx. $27 \%$.

Figure 1 shows the calculation of the cost of a rotating stock for unevenly distributed demand. In contrast, in Fig. 2 (for comparison), the calculation of the cost of the rotating stock would be presented if unequal demand in quarters were omitted. At the same time, the value of the economic order size for individual raw materials was assumed for a whole year.

From the presented calculations it is clear that if the demand is not evenly distributed (which is usually the case in production adjustment), the size of the economic order should be calculated for each period, so as not to incur unnecessary costs associated with the purchase of raw materials and/or maintenance/preservation of stocks.

\section{Discussion and conclusions}

The globalization of brands, the increasing availability of products, the ability to make purchases at the other end of the world without leaving home are just some of the opportunities offered by the modern consumer market. Its ever more dynamic development also means that gaining competitive advantages goes beyond classic norms, i.e., competing with price, availability, and quality. Modern customers are already accustomed to a large selection of goods and the privileged position in which they find themselves, and thus they expect more than just the best quality product at the lowest price. This trend is a big challenge for inventory management. Production tailored to the individual needs of the customer is difficult to predict and to precisely design.

Inventory management is one of the basic logistics functions of a production company, including planning, organisation, implementation and control of these phases of goods flow. In connection with the customisation of production that takes place in the Industry 4.0 concept and mass customisation, this type of management must be highly flexible. 
When companies adapt to the requirements of Industry 4.0 and new customer expectations, small and medium-sized manufacturing companies require special support. As these companies very often do not have large resources to purchase specialised software, an excellent inventory management tool will be presented. It is easy to reproduce and it does not require any spreadsheet.

From the analysis of the literature on the subject, it can be concluded that rotating stocks are the most important in inventory management. Their validity is, among other things, since such stocks are necessary for the proper functioning of the company and they show regular delivery and sales. The application of the presented method of calculating the rotational stock allows for wise management, elimination of unnecessary costs, all of which can be extremely useful in the era of the Industry 4.0 concept and in the need to create a smart enterprise.

Summarising the challenges posed by production personalisation in the era of Industry 4.0 for small and medium-sized enterprises, it should be noted that it is currently difficult to predict how customers' expectations will develop. Along with the development of Industry 4.0, new opportunities and threats for enterprises, as well as social expectations, appear. This creates new challenges for particular departments in the company and their management. Building a new industry is not easy, because it necessitates providing new enterprise resources. Formulating and adapting to changes is a long-term activity that requires large material and financial outlays. It increases the need for research on the problems of management of the whole supply chain in small and medium-sized enterprises operating in the era of Industry 4.0.

\section{Acknowledgements}

The author owes a debt of gratitude to Professor Jan Szymszal for his invaluable help in carrying out the research presented in this article.

\section{References}

[1] Angeleanu A., New technology trends and their transformative impact on logistics and supply chain processes, Int. J. Econ. Pract. Theor., 2015, 5 (5), 413-419.

[2] GRABOWSKA S., Improvement of the heat treatment process in the industry 4.0 context, METAL 2018, 27th International Conference on Metallurgy and Materials, Brno, Czech Republic, May 23-25, 2018, $1985-1990$.

[3] GrabowSKa S., Smart factories in the age of Industry 4.0, Manage. Syst. Prod. Eng., 2020, 28 (2), 90-96.

[4] JaCoBs R., ChaSe R., Operations and supply chain management, McGraw-Hill/Irwin, 2013, 120-130.

[5] JACOBS R., Basics of logistics in the New Era: Everything you need to know about logistics, Kindle Book, 2016.

[6] Johnson F., Flynn A., Purchasing and supply management, McGraw-Hill/Irwin, 2014, 34-45.

[7] Korena Y., ShPitalnib M., Guc P., Hu S.J., Product design for mass-individualization, Proc. CIRP, Elsevier, 2015, 36, 64-71. 
[8] KrZYŻaniaK S., Basics of inventory management in the examples, Biblioteka Logistyczna, Poznań 2005, 23-27.

[9] KuCZyŃSKa-ChaŁAdA M., SzymSZAL J., KRÓL J., Management of assortment inventory groups in selected foundry, Arch. Foundry Eng., 2014, 15 (3), 67-77.

[10] MARTIN C., Logistics and supply chain management, Pearson, 2016, 23-56.

[11] Monczka R., Handfield R., Purchasing and supply chain management, Kindle Edition, Boston 2015, 45-67.

[12] MYERSON P., Lean supply chain and logistics management (mechanical engineering), McGraw-Hill, New York 2016, 140-145.

[13] NANTERme P., DAUgherTy P., The era of the intelligent enterprise. Technology for people, Accenture, 2017.

[14] Saniuk S., Grabowska S., GajDziK B., Social expectations and market changes in the context of developing the Industry 4.0 concept, Sustainability, 2020, 12 (4), 1-20.

[15] SANIUK S., SANIUK A., CAGÁŇOVÁ D., Cyber industry networks as an environment of the Industry 4.0 implementation, Wireless Networks, 2019.

[16] SANIUK S., SANIUK A., Decision support system for rapid production order planning in production network, [In:] Advances in intelligent systems and computing, First International Conference on Intelligent Systems in Production Engineering and Maintenance, ISPEM 2017, Springer, 2018, 637, 217-226.

[17] TADEJKo P., Application of Internet of Things in logistics. Current challenges, Int. J. Comp. Int. Manuf., 2015, 7 (4), 54-64.

[18] LeE J., KaO H.-A., YANG S., Service innovation and smart analytics for Industry 4.0 and big data environment, Proc. CIRP, 2014, 16, 3-8.

[19] Fogliattoa F.S., Da Silveirab G.J.C., Borensteinc D., The mass customization decade: An updated review of the literature, Int. J. Prod. Econ., 2012, 138 (1), 14-25.

[20] Bauernhansl T., Hompel M., Vogel-Henser B., Industrie 4.0 in Produkten, Automatisierung und Logistik, Springer Fachmedien, Wiesbaden 2014.

[21] BERGER R., The Industrie 4.0 transition quantified. How the fourth industrial revolution is reshuffling the economic, social and industrial model, Roland Berger, Monachium 2016.

[22] Domingo Galindo L., The challenges of logistics 4.0 for the supply chain management and the information technology, Norwegian University of Science and Technology, May 2016.

[23] SZYMAŃSKa O., ADAMCZAK M., CYPLIK P., Logistics 4.0 - a new paradigm or set of known solutions?, Res. Log. Prod., 2017, 7 (4), 299-310. 